\title{
Effect of Duration of Cold Pretreatment and Plant Growth Regulators on Callusing and Green Plant Regeneration of Indica (Oryza sativa L.) Rice
}

\author{
Muntazir Mushtaq ${ }^{1 *}$, Anil Kumar Singh ${ }^{1}$, Romesh Kumar Salgotra ${ }^{1}$, \\ Manmohan Sharma ${ }^{1}$, R. K. Samnotra ${ }^{2}$, Vikas Sharma ${ }^{3}$, Sunali Mahajan ${ }^{4}$, \\ M. Iqbal Jeelani Bhat ${ }^{4}$ and Rizwan Yousuf ${ }^{4}$
}

${ }^{1}$ School of Biotechnology, Sher-e-Kashmir University of Agricultural Sciences and Technology of Jammu, Chatha, J\&K, 180009, India

${ }^{2}$ Division of Vegetable Science, Sher-e-Kashmir University of Agricultural Sciences and

Technology of Jammu, Chatha, J\&K, 180009, India

${ }^{3}$ Division of Biochemistry, Sher-e-Kashmir University of Agricultural Sciences and

Technology of Jammu, Chatha, J\&K, 180009, India

${ }^{4}$ Division of Statistics and Computer Science, SKUAST Science, Sher-e-Kashmir University of

Agricultural Sciences and Technology of Jammu, Chatha, J\&K, 180009, India

*Corresponding author

\section{A B S T R A C T}

\section{Keywords}

Anther culture,

In vitro, Cold

pretreatment, Plant growth regulators, Indica rice, Medium

Article Info

Accepted:

28 July 2020

Available Online:

10 August 2020
Improvement of indica rice lines is a challenging task through application of anther culture as they are recalcitrant to culture distinctive to japonica rices. Current investigation aimed to verify the effect of cold pretreatment and phytohormones on the anther culture response of 6 crosses. Cold pretreatment for $7-10$ days at $10^{\circ} \mathrm{C}$ was found to have profound effect on callus induction frequency irrespective of the media employed and the prolonged treatment over the optimum showed to be inhibitory. Of the different auxins (2,4-D, NAA) and cytokinins (Kinetin, BAP)and their combinations studied, a ratio of 1:4 for 2,4-D and NAA and 1:3:1 ratio of Kinetin: BAP: NAA ratio proved to be optimal for callus induction and green plant regeneration respectively. This information suggests the opportunity of exploiting hybrid vigor in indica rice cultivars for the development of doubled haploids with more yield and yield attributes from elite hybrid crosses.

\section{Introduction}

Emergence of anther culture technique for rice production revolutionized the field of rice breeding in the last few decades. Amongst the in-vitro culture methods, anther culture proved to be an efficient technique to crop breeding providing rapid production of doubled haploids (DHs) (Naik et al., 2017). Development of DHs through anther culture aids in rapid fixation of homozygous lines compared to conventional approaches that requires 6-7 generations of self-pollination. Double haploidy not only successfully 
reduces the breeding cycle for varietal improvement but also allow better discrimination between genotypes (Marassi et al., 2006). The recessive trait fixation in $\mathrm{DH}$ lines simplifies conductance of genetic studies. Many new cultivars and improved parental lines have been produced through androgenesis mostly in japonica hybrids, however indica rice is mostly recalcitrant to anther culture owing to poor calli induction, subsequent green plant regeneration and high albino plant regeneration, restraining the production of homozygous lines (Dewi et al., 2009; Rukmini et al., 2013; Naik et al., 2017). In order to achieve higher callus induction levels and plant regeneration potential, various factors that govern the anther culture response of indica lines under in vitro condition need to be optimized.

Although hybrid rice has gained significant importance after the green revolution with rice reaching a yield plateau, however, high seed costs and poor quality of produce have limited their use in farmer community. As rice hybrid production demands three lines system (A, B and $\mathrm{R}$ lines) in India, nonsynchronization of male and female lines also limits hybrid rice seed production. Development of fertile, stable doubled haploids from rice hybrids through androgenesis has been suggested as a feasible option, capable of generating high yielding homozygous lines in a single generation (Forster and Thomas, 2005). Thus, basic research on anther culture of indica lines assumes great implication.

Cold pre-treatment or low temperature shock has been reported to initiate sporophytic growth in several species including rice (Silva and Ratnayke, 2009; Gueye and Nidr, 2010; Sen et al., 2011; Mishra et al., 2013; Mishra et al., 2015). Cold treatment stops formation of gametes, in turn has a positive effect on the formation of callus. Cold shock causes delayed anther wall senescence, increased symmetric divisions of pollen grains and release of various compounds such as amino acids and shock-thermic proteins that aid in androgenesis (Kiviharju and Pehu, 1998; Mishra et al., 2013; Tripathi et al., 2019).

Phytohormones, mainly the auxins and cytokinins regulate dedifferentiation and differentiation processes in in vitro cultures of crop plants. Varying the tissue culture media composition, mainly by improving plant growth regulators can enhance the rate of success of anther culture (Mandal and Gupta, 1995). Among the auxins, 2, 4-D and NAA have been most frequently used for callus induction in rice because auxins play the most essential role in induction of callus from anthers of cereal crops (Zhu et al., 1998, Rukmini et al., 2013, Mukherjee et al., 2015). Better callus induction from anthers of $F_{1}$ plants derived from four crosses of aromatic and improved rice cultivars cultured in $\mathrm{N}_{6}$ and MS media supplemented with 2,4-D (0.5 mg $\left.\mathrm{L}^{-1}\right)+\mathrm{NAA}\left(1.0 \mathrm{mg} \mathrm{L}^{-1}\right)+\operatorname{BAP}\left(0.5 \mathrm{mg} \mathrm{L}^{-1}\right)$ was reported by Thuan et al., (2001).

Therefore, we in the present communication evaluated the efficiency of anthers from indica rice hybrids with cold pretreatment and culture media containing plant growth hormones on both callus induction and green plant regeneration and to ascertain the best rice hybrid suited for androgenesis.

\section{Materials and Methods}

The experimental materials were K343 x RML22, K343 x DHMAS, K39 x RML22, K39 x DHMAS, K448 x RML22 and K448 x DHMAS that were developed at the Experimental Farm of School of Biotechnology, Faculty of Agriculture, SKUAST-J, Chatha, Jammu. The boots were pulled out of the tillers in the morning hours from a healthy crop of the hybrids. The boots 
were wiped clean 2-3 times, with a clean muslin cloth moistened with with $70 \%$ alcohol. The boots were then wrapped and placed in an incubator that was maintained at $10^{0} \mathrm{C}$ for 8-10 days for cold pretreatment. On the day of culture, selected spikelets were first washed thoroughly with Tween-20 (liquid detergent) for 15 minutes and then given a dip in $70 \%$ ethanol for 2 minutes. They were then treated with $0.1 \%$ freshly prepared $\mathrm{HgCl}_{2}$ solution for 10 minutes in tissue culture bottles. The $\mathrm{HgCl}_{2}$ was drained off and the panicles were washed four times with doubledistilled water. Before culturing of anthers from a hybrid, cytological examination of microspore stages in the stages was conducted and 20-25 anthers with microspores at midnucleate to early bi-nucleate stages were uniformly dusted over the media surface.

For callus induction, $\mathrm{N}_{6}$ media (Chu 1978) supplemented with 2,4-D (1 mg/l), Kinetin $(0.5 \mathrm{mg} / \mathrm{l})$ and maltose $3 \%$ was used. The $\mathrm{pH}$ of the medium was adjusted at 5.8 using $0.1 \mathrm{~N}$ $\mathrm{NaOH}$ or $\mathrm{HCl}$ and volume made up to 1 liter. Semisolid medium, prepared by adding agar (a) $8 \mathrm{~g} \mathrm{l}^{-1}$, was autoclaved at $121^{\circ} \mathrm{C}$ temperature and 15 psi pressure for 20 minutes. For callus regeneration, MS medium (Murashige and Skoog, 1962) in readymade form, without sugar and agar, was procured from Hi-Media Laboratories. Composition of basal MS medium.. For every one litre of medium, $4.41 \mathrm{~g}$ medium and $30 \mathrm{~g}$ sucrose were added to the distilled water. Different concentrations of phytohormons i.e. cytokinins (BAP 1.0 to $2.5 \mathrm{mg} \mathrm{l}^{-1}$ and Kinetin $0.5 \mathrm{mg} \mathrm{l}^{-1}$ ) and auxins (NAA $0.5 \mathrm{mg} \mathrm{l}^{-1}$ ) were used to prepare different media combinations and assigned codes.. The $\mathrm{pH}$ of the medium was adjusted at 5.8 using $0.1 \mathrm{~N} \mathrm{NaOH}$ or $\mathrm{HCl}$ and then volume made to one liter. Agar (8 $\mathrm{g}$ $1^{-1}$ ) was used as gelling agent to prepare semisolid medium. The medium was autoclaved at $120^{\circ} \mathrm{C}$ temperature and $15 \mathrm{psi}$ pressure for 20 minutes. The pollen embryoids/calli from the anthers responding to callus induction medium were transferred onto the regeneration medium and the artificial light (2500 lux) was used to incubate the cultures for $16 / 8 \mathrm{~h}$, respectively, at $25 \pm$ $2^{0} \mathrm{C}$.

The green plantlets of around $1 \mathrm{~cm}$ in length were transferred to rooting medium for proper development of roots. For root formation in the plantlets generated from the calli, MS media augmented with NAA $(0.5 \mathrm{mg} / \mathrm{l})$, Kinetin $(0.5 \mathrm{mg} / \mathrm{l})$, maltose $(5 \%)$ and agar $(1 \%)$ was used for solidification. The fully formed plantlets were taken out from culture vessels. The agar was removed from the roots and plantlets shifted to liquid $1 / 2$ MS basal medium in larger size test tubes $(30 \times 200$ $\mathrm{mm}$ ) for proper development of roots and shoots; and incubated for 15 days under light/dark period of $16 / 8 \mathrm{~h}$, respectively, at $25 \pm 2^{0} \mathrm{C}$. After 15 days, the cotton plugs were removed and the culture vessels were left open under same culture conditions inside the culture room for another 15 days. The culture solution was changed regularly at seven days interval. The plants with fully developed roots were transferred to pots in green house.

\section{Results and Discussion}

\section{Influence of cold pretreatment}

Of the pretreatment periods evaluated after (0-11 days), both regeneration of callus and green plant regeneration were observed to be significantly higher than the control ( 0 day treatment) when the anthers were pretreated at $10^{\circ} \mathrm{C}$ for 7-11days in all the genotypes (Table 1) (Figure 1). On $\mathrm{N}_{6}$ media, both callus induction $(6.36 \%)$ and regeneration $(22.10 \%)$ were higher after 7 days cold pretreatment. The data showed that the critical pretreatment period was for 7-10 days and extending the treatment beyond 10 days showed to be inhibitory in the media used. Similar trend 
was followed for regeneration and green plant regeneration frequencies also.

\section{Effect of different combinations of phytohormones}

The experiments on callus regeneration that were conducted with callus generated on $\mathrm{N}_{6}$ induction media using different combinations of phytohormones revealed that addition of auxin: cytokinin (NAA: Kn: BAP) in the ratio of 5:1:5 (2.5: $0.5: 2.5)$ had stimulated highest regeneration $(20-22 \%)$ in all the genotypes
(Table 2) (Figure 2). The positive influence of the same ratio was marked even when the hormonal concentration was doubled (2.5:0.5:2.5 mg/l) but in the same proportion. Similar trend was observed in case of green plant regeneration $(32-36 \%)$ in all the 6 genotypes when supplemented with growth regulators in the ratio of $1: 1: 3$. While the incidence of albinos was also higher in both the genotypes in the media containing (Kn:2,4-D:BAP) in the ratio of $1: 3: 1$. Callus regenerated on hormone free media had shown very less regeneration frequency.

Fig.1 (A) Callus induction (B) Callus regeneration (C) Rooting (D) Albino plant regeneration

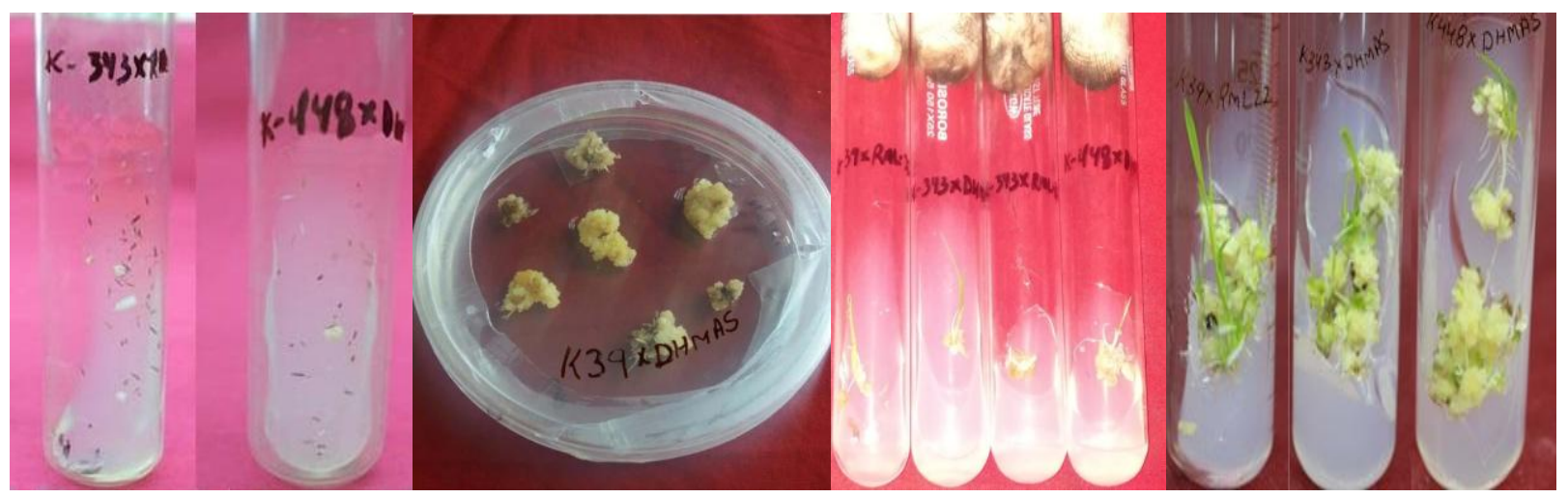

(A)

(B)

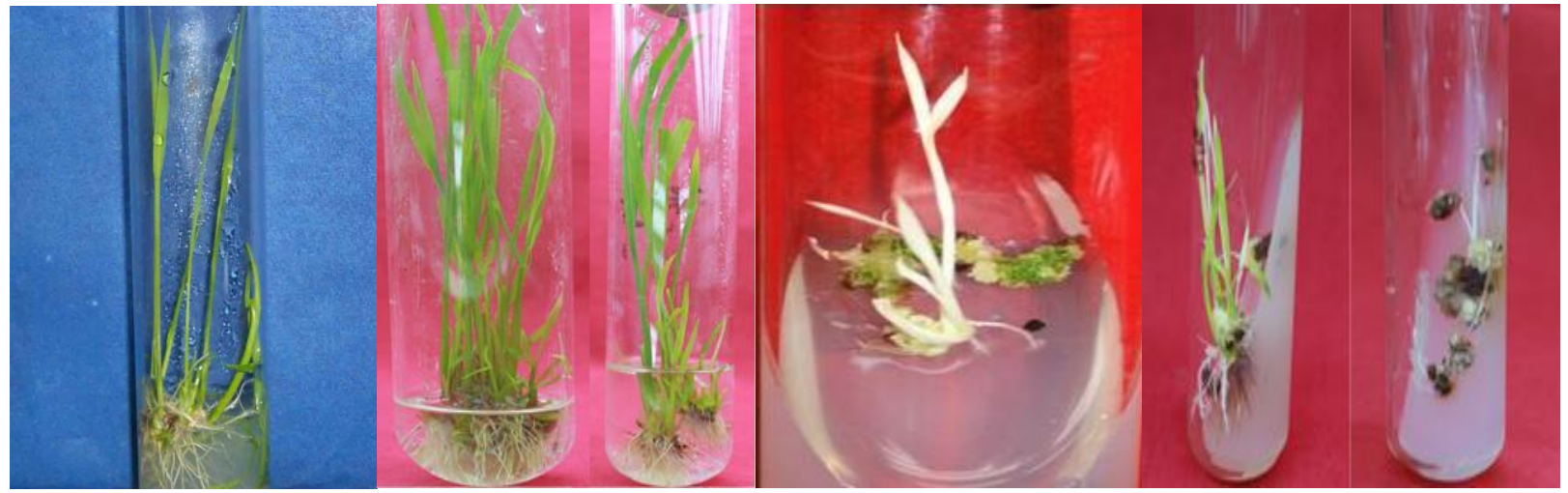

(C)

(D) 
Table.1 Effect of duration of cold pretreatment on callusing and green plant regeneration of indica (Oryza sativa L.) rice

\begin{tabular}{|c|c|c|c|c|c|c|}
\hline Genotype & $\begin{array}{c}\text { Media } \\
\text { (N6) }\end{array}$ & Days & $\begin{array}{c}\text { Callus } \\
\text { Induction }(\%)\end{array}$ & $\begin{array}{c}\text { Regeneration } \\
\%\end{array}$ & $\begin{array}{c}\text { Green plant } \\
\text { reg } \%\end{array}$ & $\begin{array}{c}\text { Albino } \\
\text { plant reg }\end{array}$ \\
\hline K343 x RML22 & N6 & 0 & 0 & 0 & 10.16 & 7.13 \\
\hline K343 x RML22 & N6 & 4 & 1.53 & 3 & 14.6 & 5.03 \\
\hline K343 x RML22 & N6 & 5 & 3.33 & 4.44 & 18.14 & 7.42 \\
\hline K343 x RML22 & N6 & 7 & 6.36 & 5.88 & 22.1 & 12.76 \\
\hline K343 x RML22 & N6 & 9 & 8.88 & 6.34 & 16.05 & 10.23 \\
\hline K343 x RML22 & N6 & 11 & 4.2 & 5 & 20 & 10.05 \\
\hline K343 x DHMAS & N6 & 0 & 0 & 0 & 9.1 & 9.18 \\
\hline K343 x DHMAS & N6 & 4 & 1.33 & 2.88 & 13.41 & 9.48 \\
\hline K343 x DHMAS & N6 & 5 & 2 & 3.1 & 19.12 & 10.87 \\
\hline K343 x DHMAS & N6 & 7 & 2.66 & 3.7 & 20.14 & 13.43 \\
\hline K343 x DHMAS & N6 & 9 & 3.57 & 5.35 & 18.14 & 11.07 \\
\hline K343 x DHMAS & N6 & 11 & 1.97 & 3.43 & 18 & 10 \\
\hline K39 x RML22 & N6 & 0 & 0 & 0 & 8.1 & 6.23 \\
\hline K39 x RML22 & N6 & 4 & 0 & 1.53 & 9.16 & 10.54 \\
\hline K39 x RML22 & N6 & 5 & 0.66 & 1.81 & 13.1 & 10.98 \\
\hline K39 x RML22 & N6 & 7 & 3.33 & 2.22 & 18.16 & 14.78 \\
\hline K39 x RML22 & N6 & 9 & 4.66 & 2.98 & 12.09 & 12 \\
\hline K39 x RML22 & N6 & 11 & 1.76 & 2 & 10 & 10.56 \\
\hline K39 x DHMAS & N6 & 0 & 0 & 0 & 8 & 6 \\
\hline K39 x DHMAS & N6 & 4 & 0 & 0 & 9.17 & 7.23 \\
\hline K39 x DHMAS & N6 & 5 & 0 & 1.3 & 11.24 & 7.56 \\
\hline K39 x DHMAS & N6 & 7 & 1.6 & 2.08 & 17.56 & 9.51 \\
\hline K39 x DHMAS & N6 & 9 & 3.33 & 3.2 & 20.1 & 8 \\
\hline K39 x DHMAS & N6 & 11 & 0.97 & 1.97 & 13.2 & 7.88 \\
\hline K448 x RML22 & N6 & 0 & 0 & 0 & 9 & 5.1 \\
\hline K448 x RML22 & N6 & 4 & 0.86 & 0 & 9.14 & 6 \\
\hline K448 x RML22 & N6 & 5 & 1.42 & 0 & 9.22 & 7.23 \\
\hline K448 x RML22 & N6 & 7 & 2 & 2.85 & 12.97 & 12.24 \\
\hline K448 x RML22 & N6 & 9 & 2.66 & 3.44 & 16.28 & 10 \\
\hline K448 x RML22 & N6 & 11 & 1.79 & 2 & 9.63 & 7.98 \\
\hline K448 × DHMAS & N6 & 0 & 0 & 0 & 8.66 & 5 \\
\hline K448 x DHMAS & N6 & 4 & 0 & 0 & 9.31 & 6.57 \\
\hline K448 x DHMAS & N6 & 5 & 2.5 & 0 & 10.09 & 10 \\
\hline K448 x DHMAS & N6 & 7 & 3.33 & 2.98 & 14.97 & 13.55 \\
\hline K448 × DHMAS & N6 & 9 & 3.84 & 3.37 & 12,32 & 10.52 \\
\hline K448 x DHMAS & N6 & 11 & 2.67 & 1.43 & 11 & 10 \\
\hline
\end{tabular}


Table.2 Effect of culture media on improving anther culture response of indica (Oryza sativa L.) rice

\begin{tabular}{|c|c|c|c|c|c|c|}
\hline Genotype & $\begin{array}{l}\text { Combinations } \\
\text { (Kn:2,4-D:BAP) (all } \\
\text { in mg-1) }\end{array}$ & $\begin{array}{c}\text { Calli } \\
\text { plated }\end{array}$ & $\begin{array}{c}\text { Calli } \\
\text { regenerated }\end{array}$ & $\begin{array}{c}\text { Regeneration } \\
\%\end{array}$ & $\begin{array}{c}\text { Green plant } \\
\text { reg }(\%)\end{array}$ & $\begin{array}{c}\text { Albino } \\
\text { reg. }(\%)\end{array}$ \\
\hline K343 x RML22 & $0: 0+0+$ maltose & 110 & 12 & 10.9 & 6.9 & 4 \\
\hline K343 x RML22 & 1.0:0.5+1.0+maltose & 90 & 35 & 38.8 & 23.12 & 15.68 \\
\hline K343 x RML22 & 1.5:0.5+1.5+maltose & 100 & 29 & 29 & 17.3 & 11.7 \\
\hline K343 x RML22 & 2.0:0.5+2.0+maltose & 105 & 26 & 24.63 & 15.32 & 9.31 \\
\hline K343 x RML22 & 2.5:0.5+2.5+maltose & 125 & 18 & 14.4 & 8.5 & 5.9 \\
\hline K343 x DHMAS & $0: 0+0+$ maltose & 100 & 10 & 10 & 5.6 & 4.4 \\
\hline K343 x DHMAS & 1.0:0.5+1.0+maltose & 100 & 7 & 7 & 5.2 & 1.8 \\
\hline K343 x DHMAS & 1.5:0.5+1.5+maltose & 110 & 13 & 11.81 & 8.61 & 3.2 \\
\hline K343 x DHMAS & 2.0:0.5+2.0+maltose & 105 & 19 & 18.09 & 12.09 & 6 \\
\hline K343 x DHMAS & 2.5:0.5+2.5+maltose & 90 & 12 & 13.4 & 10.4 & 3 \\
\hline K39 x RML22 & $0: 0+0+$ maltose & 105 & 16 & 15.23 & 8.73 & 6.5 \\
\hline K39 x RML22 & 1.0:0.5+1.0+maltose & 105 & 14 & 13.4 & 9.7 & 3.7 \\
\hline K39 x RML22 & 1.5:0.5+1.5+maltose & 110 & 10 & 9.09 & 5.9 & 3.19 \\
\hline K39 x RML22 & 2.0:0.5+2.0+maltose & 100 & 24 & 24 & 15.09 & 8.91 \\
\hline K39 x RML22 & 2.5:0.5+2.5+maltose & 100 & 20 & 20 & 12 & 8 \\
\hline K39 x DHMAS & $0: 0+0+$ maltose & 90 & 7 & 7.8 & 4.9 & 2.9 \\
\hline K39 x DHMAS & 1.0:0.5+1.0+maltose & 100 & 14 & 14 & 9.61 & 4.39 \\
\hline K39 x DHMAS & 1.5:0.5+1.5+maltose & 70 & 10 & 14.28 & 8.5 & 5.78 \\
\hline K39 x DHMAS & 2.0:0.5+2.0+maltose & 120 & 12 & 10 & 6.3 & 3.7 \\
\hline K39 $\times$ DHMAS & 2.5:0.5+2.5+maltose & 110 & 24 & 21.81 & 14.5 & 7.31 \\
\hline K343 x RML22 & $0: 0+0+$ maltose & 125 & 12 & 9.6 & 5.9 & 3.7 \\
\hline K448 x RML22 & 1.0:0.5+1.0+maltose & 120 & 17 & 14.17 & 8.2 & 5.97 \\
\hline K448 x RML22 & 1.5:0.5+1.5+maltose & 110 & 19 & 17.27 & 9.8 & 7.47 \\
\hline K448 x RML22 & 2.0:0.5+2.0+maltose & 100 & 23 & 23 & 14.56 & 8.44 \\
\hline K448 x RML22 & 2.5:0.5+2.5+maltose & 115 & 28 & 24.34 & 13.2 & 10.14 \\
\hline K448 x DHMAS & $0: 0+0+$ maltose & 100 & 7 & 7 & 4.2 & 2.8 \\
\hline K448 x DHMAS & 1.0:0.5+1.0+maltose & 95 & 12 & 12.63 & 7.8 & 4.83 \\
\hline K448 x DHMAS & 1.5:0.5+1.5+maltose & 100 & 15 & 15 & 9.1 & 5.9 \\
\hline K448 x DHMAS & 2.0:0.5+2.0+maltose & 110 & 20 & 18.18 & 10 & 8.18 \\
\hline K448 x DHMAS & 2.5:0.5+2.5+maltose & 100 & 13 & 13 & 7.6 & 5.4 \\
\hline
\end{tabular}


Fig.2 Effect of different combinations of phytohormones on callusing and green plant regeneration of indica (Oryza sativa L.) rice

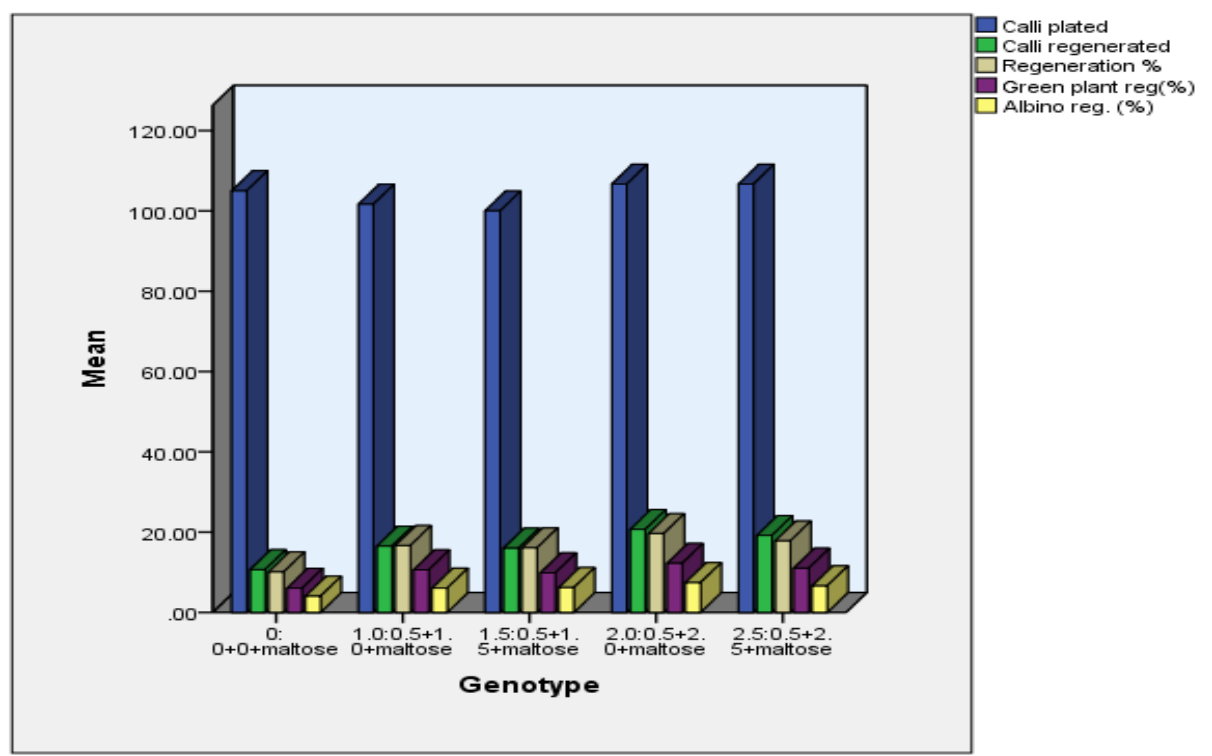

The results suggest that the cold pretreatment was found to have a positive influence on the callus induction frequency irrespective of the media employed and a 7-11 day period of cold shock at $10^{\circ} \mathrm{C}$ was found to be optimal for all the genotypes tested and any extended treatment over the optimum proved to be inhibitory. The treatment resulted in 2-4 fold increase in callus induction but also resulted in early $(\sim 10-12 \mathrm{~d})$ callus induction. Our results were similar to previous findings (Lenka and Reddy, 1993: Rukmini et al., 2013) which also described the inhibitory effect of prolonged period of pretreatment. The positive effect of cold shock was also reported in other crop species such as flax (Orbert et al., 2005) and rye (Roininen et al., 2005). Although, Xie et al., (1995) recommended a cold pretreatment $\left(4-13^{0} \mathrm{C}\right)$ for 7-28 days to induce callus, various results including the present one do not support such a view.

Albino plant production is one of the main problems in rice anther culture (Khatun et al., 2012; Rukmini et al., 2013). Though the albino formation did not follow any pattern in relation to the cold shock duration in the present study, reports indicate that prolonged pretreatment has adverse effect on green plant formation and significant increase in albino production (Gupta and Borthakur, 1987). Cold shock is stated to enhance the stoppage of the gametophytic development of microspores during cold shock pretreatment and help in continuous division of microspores into forming callus/embryo (Touraev et al., 1996: Rukmini et al., 2013) and this shift from gametophytic mode may cause instability and the loss of chlorophyll is a manifestation of that shift.

The most important constituents in the rice anther culture medium were auxins and cytokinins. Auxins have been essential plant growth regulators for the callus induction from anthers of cereals (Zhu et al., 1998) and the type and level of the auxin present in culture medium regulates the callus formation. Of the several phytohormonal combinations evaluated in the induction media, a ratio of $1: 4$ for $\mathrm{Kn}$ : 2,4-D was proved to be beneficial for androgenesis while the phytohormonal combination of Kn: 2,4-D: 
BAP in the ratio of $1: 3: 1 \quad(0.25: 0.75: 0.25$ $\mathrm{mg} / \mathrm{l})$ has proved to be optimal for obtaining high green plant regeneration. The current communication supports the opinion of Raina and Iyer (1974) that ideal phytohormonal combination was needed for ideal regeneration of 2,4-D induced calli. TrejoTapia et al., (2002) reported auxins were essential for the callus induction from anthers and suggested that the type and concentration of auxins have influence on the induction of calli.

In conclusion as several physical and chemical factors influence the genotype response to culture, the investigation studied two major factors: cold pretreatment to the anthers prior to their culture and the plant growth regulator combinations in culture media. The study determines that cold shock has advantageous effects on the callus induction and a pretreatment for 7-11 days at $10^{\circ} \mathrm{C}$ showed a positive influence. The results showed the negative influence on callus induction frequency irrespective of the media employed and prolonged cold treatments above the optimum. A combination of auxins and cytokinins (Kn: 2,4-D: BAP) in the regeneration medium have a profound positive influence on the regeneration.

\section{Acknowledgements}

First author is thankful to Coordinator, School of Biotechnology for support and encouragement and SKUAST-J for providing facilities to carry out the present study.

\section{References}

Dewi, I.S., Purwoko, B.S., Aswidinnoor, H., Somantri, I. H., Chozin, M. A.,2009, Plant regeneration from anther cultures of several genotypes of indica rice tolerant to aluminum toxicity. Indones J Agric Sci, 2:1-5.

Forster, B. P., Thomas, W. T. B., 2005, Doubled haploids in genetics and plant breeding. Plant Breed, 25:57-88.

Gueye, T., Ndir, K. N., 2010, In vitro production of double haploid plants from two rice species (Oryza sativa L. and Oryza glaberrima Steudt.) for the rapid development of new breeding material. Scientific Research and Essays. 5(7):709713.

Gupta, H. S., Borthakur, D. N., 1987, Improved rate of callus induction from rice anther culture following microscopic staging of microspores in iron alum-haemotoxylin. Theoretical \& Applied Genetics,74: 9599.

Khatun, R., Shahinul Islam, S. M., Ara, I., Tuteja, T., Bari, M. A., 2012, Effect of cold treatment and different media in improving anther culture response in rice (O. sativa $\mathrm{L}$ ). in Bangladesh. Indian Journal of Biotechnology, 11: 458-463.

Kiviharju E, Pehu E (1998) The effect cold and heat pretreatments on anther culture response of Avena sativa and A. sterilis. Plant Cell Tissue and Organ Culture 54: 97-104.

Lenka, N., Reddy, G. M., 1994, Role of media, plant growth regulators in callusing and plant regeneration from anthers of indica rice. Proceedings of the Indian National Academy of Sciences, 60: 87-92.

Mandal, N., Gupta, S., 1995, Effect of and culture medium on androgenic callus formation and green plant regeneration in indica rice. Indian Journal of Experimental Biology, 33: 761-765.

Marassi, M. A, Scocchi, A, Gonzalez, A. M., 2006, Plant regeneration from rice cryopreserved by an encapsulation/ dehydration technique. In vitro Cell Dev Biol Plant, 42:31-36.

Mishra, R., Rao, G. J. N., Rao, R. N., Kaushal, P., 2015, Development and characterization of elite doubled haploid lines from two indica rice hybrids. Rice Sci. 22:290-299.

Mukherjee, A., Islam, M. R., Nasiruddin, K. M., Banerjee, P., 2015, Study on callus initiation and plantlet regeneration ability of some rice genotypes. International Journal of Science \&Technology Research, 4(10): 354-361. 
Murashige, T., Skoog, F., 1962, A revised medium for rapid growth and bioassay with tobacco tissue cultures. Physiologia Plantarum, 15: 473-497.

Naik, N., Rout, P., Umakanta, M., Verma, R. L., et al., 2017, Development of doubled haploids from an elite indica rice hybrid (BS6444G) using anther culture. Plant Cell Tiss Organ Cult, 127: 679-689.

Obert, B., Dedieova, B., Hricova, A., Sama, J., Pretova, A., 2005, Flax anther culture: effect of genotype, cold treatment and media. Plant Cell Tissue and Organ Culture, 79(2): 233-238.

Raina, S. K., Iyer, R. D., 1974, A study of response to anther culture. Indian Journal of Genetics and Plant Breeding, 34 A: 283-285.

Roininen, I. T., Tanhuanpaa, P., Immonen, S., 2005, The effect of cold and heat treatments on the anther culture response of diverse rye genotypes. Euphytica, 145: $1-9$.

Rukmini, M., Rao, G. J. N., Rao, R. N., 2013, Effect of cold pretreatment and phytohormones on anther culture efficiency of two indica rice (Oryza sativa L.) hybrids- Ajay and Rajalaxmi. Journal of Experimental Biology and Agricultural Sciences, http://www.jebas.org.

Sen, C., Singh, R. P, Singh, M. K., Singh, H. B., 2011, Effect of Cold Pre-treatment on Anther culture of Boro Rice Hybrids. The International Journal of Plant Reproductive Biology, 3: 69-73.

Silva, T. D., Ratnayake, W. J., 2009, Anther culture potential of indica rice varieties Kurulu Thuda and BG 250. Tropical Agricultural Research and Extension, 12: 54-56.
Thuan, O. T., Tuan, V. D., Ba Bong, B., 2001, Study on anther culture of $F_{1}$ plants from crosses between aromatic and improved rice cultivars. Omonrice, 9: 41-45.

Touraev, A., Indriato, A., Wratschko, I., Vicente, O., Heberle- Bors, E., 1996. Efficient microspore embryogenesis in wheat (Triticum aestivum L.) induced by starvation at high temperature. Sexual Plant Reproduction, 9: 209-215.

Trejo-Tapia, G., Amaya, U. M., Morales, G. S., Sanchez, A. D. J., Bonfil, B. M., Rodriguez-Monroy, M., JimenezAparicio, A., 2002, The effects of coldpretreatment, auxins and carbon source on anther culture of rice. Plant Cell Tissue and Organ Culture, 71: 41-46.

Tripathy, S. K., Lenka, D., Prusti, A. M., Swain, D., Behera, S. K., 2019, Anther culture in rice: progress and breeding perspective. Applied Biological Research, 21(2): 87104.

Xie, J. H., Gao, M., Cai, Q., Sheng, X., Shen, Y., Liang, Z., 1995, Improved isolated microspore culture efficiency in medium with maltose and optimized growth regulator combination in japonica rice (Oryza sativa). Plant Cell Tissue and Organ Culture, 42: 245-250.

Zhu, D. Y., Sun, Z. X., Pan, X. G., Ding, X. H., Shen, X. H., Won, Y., Pan, H., Yin, J. H., Alejar, M. S., Torrizo, L. B.,Datta, S. K., 1998, Use of anther culture in hybrid rice breeding. Proceedings of the 3rd International Symposium of Hybrid Rice 14-16 Nov 1996. Hyderabad, India. In: Advances in Hybrid Rice Technology. International Rice Research Institute, Manila (Philippines). 21: 265-281.

\section{How to cite this article:}

Muntazir Mushtaq, Anil Kumar Singh, Romesh Kumar Salgotra, Manmohan Sharma, R. K. Samnotra, Vikas Sharma, Sunali Mahajan, M. Iqbal Jeelani Bhat and Rizwan Yousuf. 2020. Effect of Duration of Cold Pretreatment and Plant Growth Regulators on Callusing and Green Plant Regeneration of Indica (Oryza sativa L.) Rice. Int.J.Curr.Microbiol.App.Sci. 9(08): 39553963. doi: https://doi.org/10.20546/ijcmas.2020.908.455 